\section{A negociação de saberes em um contexto de formação inicial de professores de Língua Inglesa}

The negotiation of knowledge in the context of initial education of English language teachers

\section{Themis Rondão Barbosa da Costa Silva (iD) 9}

themis.barbosa@ifms.edu.br

Universidade Estadual de Campinas - UNICAMP

\section{Resumo}

Este artigo é um recorte de minha dissertação de mestrado que teve por objetivo principal investigar a formação de professores de Língua Inglesa em contexto de um Subprojeto vinculado ao Programa Institucional de Bolsas de Iniciação à Docência (Pibid). Trata-se de pesquisa de natureza qualitativa de cunho etnográfico, com características de epistemologia da emergência. A pesquisa foi desenvolvida em contexto de uma escola pública da cidade de Campo Grande - MS e teve como participantes uma professora supervisora da escola, quatro licenciandos do Pibid e esta pesquisadora. Os dados foram coletados por meio de gravações em áudio e/ou em vídeo das reuniões de planejamento e aulas, questionários e entrevistas com os participantes. A análise consiste, principalmente, na descrição dos aspectos emergentes ao longo do processo de formação investigado e suas interfaces com a formação de professores na contemporaneidade. A pesquisa indicou que o enfraquecimento de hierarquias entre pesquisador, pesquisado e licenciandos, por meio de uma ressignificação da relação entre escola e universidade e seus saberes, resultou em práticas colaborativas ao longo do processo de formação de professores.

\section{Palavras-chave}

Formação de professores. Língua Inglesa. Pibid. Linguística Aplicada. Letramentos.

\section{Abstract}

This article is an excerpt from my master's dissertation whose main objective was to investigate English language teachers education in the context of a Subproject linked to the Institutional Program for Teaching Initiation Scholarships (Pibid). This is a qualitative and ethnographic research with characteristics of emergency epistemology. The research was developed in the context of a public school in Campo Grande - MS. Participants were an English teacher, four Pibid university students and this researcher. Data were collected through audio and/or video recordings of meetings and classes, questionnaires and interviews. Analyses have particularly addressed the description of emergent aspects during the processes of investigation and their interfaces with teacher development. Research findings have indicated the weakening of hierarchies among researcher, teacher and students, through reconceptualization of the relationship between school and university and their knowledges have resulted from collaborative practices through the process the of teacher education.

\section{Keywords}

Teacher education. English Language. Pibid. Applied Linguistics. Liter-

\section{Linguagęm Foco}

Revista do Programa de Pós-Graduação em Linguística Aplicada da UECE

FLUXO DA SUBMISSÃO

Submissão do trabalho: $26 / 02 / 2021$ Aprovação do trabalho: 20/04/2021 Publicação do trabalho: 04/06/2021

\section{COMO CITAR}

SILVA, Themis Rondão Barbosa da Costa. A negociação de saberes em um contexto de formação inicial de professores de Língua Inglesa. Revista Linguagem em Foco, v.13, n.1, 2021. p. 201-220. Disponível em: https://revistas.uece.br/index. php/linguagememfoco/article/ view/4950. 
acies.

\section{Introdução}

"Não há saber mais, nem saber menos, há saberes diferentes".

(FREIRE, 1987, p. 68).

O conhecimento científico é considerado, oficialmente, a forma privilegiada de conhecimento e sua importância para a vida das sociedades contemporâneas é incontestável (SANTOS, 2010). Entretanto, partindo do pressuposto de que todos os conhecimentos são contextuais e parciais, Santos (2010) defende que não há conhecimentos puros ou completos, mas há constelações de conhecimentos. Nesse sentido, segundo o autor, "importa construir um modo verdadeiramente dialógico de engajamento permanente, articulando as estruturas do saber moderno/científico/ocidental às formações nativas/locais/tradicionais de conhecimento" (SANTOS, 2010, p. 154). Ainda na visão desse autor, o reconhecimento e a valorização da infinita pluralidade dos saberes e a luta contra uma monocultura do saber interfere na realização de ações verdadeiramente emancipatórias.

Baseado no reconhecimento da pluralidade de conhecimentos heterogêneos e as interações entre eles, Santos (2010) propõe o conceito de ecologia de saberes. De acordo com o autor, essa ecologia consiste em "um conjunto de epistemologias que partem da possibilidade da diversidade e da globalização contra-hegemônicas e pretendem contribuir para as credibilizar e fortalecer" (SANTOS, 2010, p. 154). Fundamentada nessa perspectiva teórica, por meio de um olhar situado, discuto as negociações de saberes entre os participantes de minha pesquisa de mestrado' e o que emerge a partir de suas relações.

Os dados foram coletados em um contexto de formação inicial de professores de Língua Inglesa em escola pública. Durante seus processos de formação, quatro licenciandos participantes do Programa Institucional de Bolsas de Iniciação à Docência (Pibid²) foram supervisionados por uma professora da Escola Estadual J. M. H. R, localizada na cidade de Campo Grande - MS. A pesquisa transcorreu entre os meses de abril e dezembro de 2014. Para coleta de dados foram utilizadas gravações em áudio e/ou em vídeo das reuniões de planejamento e aulas, questionários e entrevistas com os participantes da pesquisa. A fim de facilitar a comunicação e o compartilhamento de arquivos entre os participantes, foi 
criado um grupo fechado no Facebook e no Whatsapp. Esses foram dois canais muito eficientes e bastante utilizados para socializar teorias, sugerir temas, imagens, vídeos e materiais para elaboração das aulas e ainda para compartilhar as apresentações em arquivo padrão do Microsoft PowerPoint (PPT) utilizadas nas aulas, produções dos estudantes, fotos, sites e ferramentas on-line de aprendizagem.

Ressalto que meu objetivo, neste artigo, não é apresentar o histórico ou prescrever caminhos e soluções para a formação de professores, temática já largamente discutida por renomados teóricos nacionais e internacionais. $\bigcirc$ que pretendo é expor possíveis características de um profissional que seja capaz de proporcionar a seus estudantes formação em perspectiva mais ampla do que a oferecida por aqueles que ainda preservam um conceito de educação tradicional, conteudista e, muitas vezes, descontextualizada.

Logo, o que apresento nas próximas seções são possibilidades à formação de um professor capaz de compreender que, nos dias de hoje, as diferentes formas de construir sentidos e as diferentes formas de vida, nesse mundo globalizado e complexo em que vivemos, requerem diferentes posturas e formas de ensinar. Desse modo, primeiramente, apresento algumas considerações sobre formação de professores. Em seguida, aponto aspectos que emergiram durante o processo de formação investigado que, na minha visão, representam possibilidades para a formação docente na contemporaneidade.

A partir dessas teorizações e da análise dos dados obtidos, pretendo neste trabalho, identificar as implicações da relação estabelecida entre os participantes da pesquisa na formação dos licenciandos e averiguar como a agência pode ser desenvolvida a partir do processo colaborativo entre os participantes.

\section{A formação de professores na contemporaneidade}

"If we are to have 'new learners', we need nothing less 'new teachers'".

(KALANTZIS; COPE, 2012, p. 11).

A crescente preocupação com a transformação social na educação e com as diferentes formas de produzir conhecimento, segundo Miller (2013), aponta para a busca por formar, no século XXI, um professor crítico e ético, bem como por investigar sua formação. A mudança na responsabilidade profissional do professor também é discutida por Menezes de Souza (2011). Segundo esse autor, no 
"mundo de hoje" a que ele se refere como um mundo globalizado, múltiplo e de complexidades, o professor se torna cada vez mais responsável sobre sua atuação como educador. Esse mundo requer do professor uma atuação diferente em sala de aula, diante de sua complexidade. Nesse sentido, nesta seção, apresento algumas reflexões sobre o papel e a formação de professores para o cenário atual.

Em um contexto de rápidas transformações, surgem questionamentos em relação ao tipo de formação docente que pode possibilitar ao professor um olhar sobre o seu entorno e suscitar reflexões sobre diferentes formas de ensinar. Essas considerações, segundo Silva (2012), requerem uma revisão no processo de formação inicial do professor. Para a autora, os cursos de formação de professores, construídos a partir de paradigmas formais externos aos docentes, podem não corresponder ao cenário em que vivemos, uma vez que mantêm caráter de treinamento e visam a formar profissionais executores. Em outras palavras, a proposta de cursos nessa vertente é treinar professores para colocar em prática orientações de currículos concebidos de forma descontextualizada. Nesse mesmo raciocínio, ela critica o modelo de educação unificadora e homogeneizadora que apaga diferenças culturais e semiótico-modais. Como alternativa, a autora propõe que a formação de professores tenha

[...] imbricados o desenvolvimento da crítica, entendida como a desconstrução de discursos cristalizados, e o espaço para reflexão, de modo a promover nesses profissionais em formação uma perspectiva crítica para o processo de ensino-aprendizagem de inglês, e proporcionar uma visão que exacerbe o caráter instrumental da língua, para entender as conexões entre língua, cultura, poder, modalidades de produção de sentidos, pluralismo e comunicação (SILVA, 2012, p. 21).

A partir dessas reflexões, Silva (2012) sugere uma escola em constante transformação e revisão de seus valores e a atuação de professores como ferramenta crítica voltada às especificidades locais. Em consonância com a autora, Duboc (2012, p. 74) afirma que formar um professor de inglês envolve, dentre outros objetivos, "tratar das formas de produção e interpretação de sentidos nos usos das linguagens, suas diferentes formas representacionais, os diferentes discursos nos quais nos inscrevemos e toda uma série de aspectos inerentes à disciplina". Em outras palavras, a formação docente proposta por Silva (2012) e Duboc (2012) visa a formar um professor que considera aspectos de seu entorno, além de contribuir para a formação crítica no que diz respeito às futuras escolhas que serão feitas por esse profissional em sua prática pedagógica.

Seguindo a proposta educacional dos novos letramentos, esses 'novos' 
professores são apontados por Kalantzis e Cope (2012, p. 11, tradução minha) como "designers de ambientes de aprendizagem para alunos engajados, mais do que pessoas que regurgitam o conteúdo do livro didático3". Na visão dos autores, os professores são profissionais capazes de criar condições em que os aprendizes assumam mais responsabilidade pelas suas próprias aprendizagens. Nessa mesma perspectiva, Jordão e Fogaça (2007, p. 91) defendem que o papel do professor seja

[...] dar oportunidades aos alunos de construir e negociar significados de forma coletiva, de rever suas crenças e de questionar as implicações de suas visões de mundo. A criação de tais oportunidades em sala de aula está diretamente relacionada à forma como o professor conduz sua aula e suas atitudes em relação ao que ocorre dentro e fora da escola: dependendo da postura do professor na sala de aula, os alunos podem ter mais ou menos espaço para questionar e transformar significados, criando outros ou aceitando os sentidos construídos por outras pessoas na tentativa de reler o mundo.

A criação das oportunidades sugeridas por Jordão e Fogaça (2007) relaciona-se à postura do professor na condução de suas aulas e a seu olhar para o contexto escolar, assim como para a vida dos alunos. Essas oportunidades podem, segundo os autores, ser momentos propícios a questionamentos, revisão de crenças e transformação de significados construídos pelos alunos ou por outras pessoas.

Nesse mesmo entendimento, ao tratar do papel do professor, Duboc (2011) destaca a importância de ensinar os alunos a se relacionar com o mundo e a pensá-lo de formas diferentes, vestindo as lentes do outro. Essas são habilidades importantes em uma sociedade que requer dos alunos a capacidade de lidar com conflitos que são gerados pelas diferenças e de visualizar múltiplas perspectivas sobre diversas questões. As Orientações Curriculares para o Ensino Médio para Língua Estrangeira (OCEM-LE) (BRASIL, 2006, p. 98) propõem que o professor leve os alunos "à compreensão de que os conflitos e as contradições fazem parte das relações sociais e da complexidade destas, fazendo parte portanto da heterogeneidade social". Para compreensão dessa heterogeneidade social, Geertz (2001 apud MONTE MÓR, 2008, p. 177) sugere "modos de pensar que sejam receptivos às particularidades, às individualidades, às estranhezas, descontinuidades, contrastes e singularidades [...]", uma pluralidade de maneiras de fazer parte e de ser [...]". Nesse sentido, percebo a criação de oportunidades (JORDÃO; FOGAÇA,

3 (The new teachers are) designers of learning environments for engaged students, rather the people who regurgitate the content of the textbook. 
2007) durante o processo de design de ambientes de aprendizagem (KALANTZIS; COPE, 2012) como possibilidade à ampliação de perspectivas dos alunos em relação a essas questões.

A concepção desses ambientes de aprendizagem nesse cenário de heterogeneidades, gerando mudanças na comunicação e na construção de conhecimento, aponta para reflexões ainda mais amplas sobre o papel da educação. O uso de práticas pedagógicas tradicionais, por exemplo, que entendem que o professor é o detentor das informações e deve transferi-las para aqueles que não as possuem ${ }^{4}$, pode não ser suficiente à formação de indivíduos que tenham condições de participar criticamente nesse contexto.

As perspectivas teóricas dos letramentos visam a revisar os modelos tradicionais de educação. De acordo com esses estudos, o que o aluno traz para o ato de ler é valorizado e o ensino da leitura deve ser acompanhado pelo ensino da cultura. Nessa perspectiva, os leitores devem ser incentivados a compreender representações textuais, valores, ideologias, ter visões de mundo e posicionar-se, entendendo que a leitura está relacionada com conhecimento e distribuição de poder em uma sociedade (FREEBODY; LUKE, 1997 apud MONTE MÓR, 2007).

A complexidade de ensinar pessoas a ler e escrever dentro de uma sala de aula permeada por diferentes valores é discutida por Menezes de Souza (2011). Para o autor, ensinar os aprendizes a lidar com as diferenças sociais sem querer eliminá-las é uma questão de responsabilidade ética. Ao tratar da relação entre ética e educação, Todd (2003, p. 1) defende que qualquer modelo de educação que leve a sério questões de justiça social terá como ponto central o discurso ético de "repensar relações com as outras pessoas". Segundo ela,

A magnitude das violentas realidades vividas por desabrigados, a pobreza, o sexismo, a injustiça racial, e genocídio é, para mim, a razão por que a ética não só exige atenção imediata, mas por que a educação precisa se preocupar com a ética (TODD, 2003, p.1, tradução minha) ${ }^{5}$.

Na visão da autora, um trabalho conjunto entre ética e educação pode apontar caminhos que possibilitem um "viver bem juntos". Essa união ocorre por meio de uma educação para a justiça social, que envolve aquelas pedagogias que buscam amenizar os danos sociais causados por práticas e estruturas injustas (TODD, 2003). A autora enfatiza ainda que

4 Concepção de educação denominada por Freire (1987) como "educação bancária".

5 The magnitude of violently lived realities of homelessness, poverty, sexism, racial injustice, and genocide is, to me, the very reason why ethics not only demands immediate attention, but why education needs to concern itself with ethics. 
A educação para a justiça social tem sido e continua a ser marcada por uma preocupação moral com aqueles que foram "alterizados" e marginalizados por meio de relações discriminatórias que são vistas como violentas, tanto em termos materiais quanto simbólicos. Muitas vezes definida por meio de categorias sociais de identidade, diferença e comunidade, esta figura do "Outro" ocupa um especial, e central, lugar em ambas as abordagens teóricas e práticas para tais iniciativas pedagógicas (TODD, 2003, p. 1, tradução minha) ${ }^{6}$.

Nos termos da educação para a justiça social, "Outro" é visto como consequência da desfiliação social, política e econômica (TODD, 2003). O valor e o significado atribuídos ao 'outro', segundo Menezes de Souza (2011), vem do contexto em que o 'eu' está situado, ou seja, das comunidades às quais pertence. Essas comunidades podem ser culturais, de classe social, de gênero, de origem geográfica, dentre outras, e são elas que oferecem a esse 'eu' diferentes categorias que o levam à produção de significados. Nessa mesma perspectiva, as OCEM-LE ressaltam que

É importante lembrar que qualquer membro de "uma cultura" pertence simultaneamente a diversos desses grupos [regionais, sócio-econômicos, de gêneros, religiosos, de imigrantes, urbanos, rurais, etc.] e, portanto, possui e usa simultaneamente diversos conjuntos de valores e crenças (BRASIL, 2006, p. 102).

O entendimento de que as identidades são complexas, dinâmicas e historicizadas e a expansão do conhecimento de si próprio, de acordo com Takaki (2011)7, são possibilitados por meio de uma relação complexa e de diálogos com o outro. Associo essa discussão aos posicionamentos de Mattos e Valério (2010, p. 142). As autoras defendem que

O desenvolvimento intercultural (CRAWSHAW, 2005), então, se dá por intermédio
do conhecimento e da compreensão das diferenças, sem, no entanto, abrir-se mão
de valores, exatamente como propõem as OCEM (2006); muito pelo contrário, pois
o Eu só se constrói em oposição ao Outro. Portanto, só a percepção de outros va-
lores, não como desvios, mas como próprios de nossas culturas, podem nos dar
melhor noção da heterogeneidade presente em nossa própria identidade.

6 Social justice education has been and continues to be marked by a moral concern with those who have been "Othered" and marginalized through discriminatory relations that are seen as violent, both in symbolic and material terms. Often defined through social categories of identity, difference, and community this figure of the "Other" occupies a special, and central, place in both theoretical and practical approaches to such pedagogical initiatives.

7 Entrevista em vídeo "Letramentos críticos e formação de professores" (2011). Disponível em: https:// vimeo.com/31867220 
A percepção da heterogeneidade presente em nossa própria identidade, segundo as autoras, se constrói na relação com o Outro. Nesse mesmo raciocínio, para promover reflexões a respeito da heterogeneidade nas sociedades contemporâneas, Monte Mór (2010) propõe, para o ensino de língua estrangeira, um trabalho pedagógico com três perspectivas: pessoal, comunitária e global.

Na perspectiva pessoal, o aluno é incentivado a perceber, por meio de discussões e reflexões, que "todo cidadão é um sujeito socialmente constituído e não uma individualidade desvinculada dos outros" (MONTE MÓR, 2010, p. 46), aprendendo desta maneira a perceber e valorizar as semelhanças e diferenças. Na comunitária, os indivíduos são vistos como membros de grupos e coletividades sociais. Logo, essa perspectiva objetiva "sensibilizar o aluno para o fato de que semelhanças e diferenças de opiniões, atividades e valores têm origem nos contextos e grupos sociais aos quais cada um pertence" (MONTE MÓR, 2010, p. 47). Já na perspectiva global, "procura-se sensibilizar o aluno a respeito das semelhanças/diferenças e da interação local/global entre grupos de várias culturas e nações" (MONTE MÓR, 2010, p. 48). Nessa concepção, o aluno é levado a compreender a diversidade e a heterogeneidade que há em grandes grupos, como nações, buscando desfazer estereótipos discriminatórios.

Nesse sentido, o professor de língua estrangeira, por meio de uma atuação crítica e ética, pode proporcionar a formação de seus alunos em perspectiva mais ampla, indo além do desenvolvimento de habilidades linguísticas específicas. Para tanto, as OCEM-LE (BRASIL, 2006, p. 90) sugerem que, por meio de reflexões sobre a relevância da noção de cidadania e práticas socioculturais contextualizadas de ensino, a sala de aula torne-se um espaço para "o desenvolvimento da consciência social, criatividade, mente aberta para conhecimentos novos, enfim, uma reforma na maneira de pensar e ver o mundo".

Nesta seção, abordei questões relacionadas ao perfil e à atuação do professor frente às complexidades do mundo em que vivemos. Na próxima seção, A negociação de saberes entre os participantes da pesquisa, discorro sobre a postura da professora supervisora na condução do processo formativo dos licenciandos e suas implicações.

\section{A negociação de saberes entre os participantes da pesquisa}

Eu acho bem positivo ter alguém [licenciandos] na escola que tá estudando! Até os alunos têm muito respeito por eles, conhecem, eles perguntam, confiam neles também. Às vezes eu não tô por perto, eles perguntam pros estagiários, então assim, é positivo porque eles estão em contato com as 
matérias da faculdade, né? Que faz quanto tempo que eu não leio, então eles podem também, essa troca, escola-faculdade, faculdade-escola, eu tenho certeza que eles podem acrescentar várias coisas aqui na escola! (PROFESSORA LARISSA).

Após breve introdução, inicio esta seção com um recorte da entrevista concedida pela professora Larissa no encerramento das atividades da etapa investigada do Subprojeto Letras - Inglês do Pibid. No trecho apresentado acima, a fala da professora aponta para uma questão sobre a qual refleti ao longo de toda minha pesquisa de mestrado, a relação entre a pluralidade de conhecimentos heterogêneos. Noto, no excerto, que a professora valoriza os conhecimentos trazidos pelos licenciandos e vislumbra a possibilidade de troca de saberes. Larissa enfatiza também que tanto os conhecimentos oriundos da universidade podem contribuir com a escola, quanto os conhecimentos da escola podem contribuir para a universidade 8 .

Remeto essa reflexão às considerações de Rancière (2007) a respeito da igualdade das inteligências. A partir da premissa da igualdade dos seres, o autor aponta que a compreensão de que somos essencialmente iguais permite a compreensão mútua, a transformação das relações dos indivíduos, bem como seu desenvolvimento. Nessa perspectiva, a desigualdade da inteligência consiste na crença de que os superiores de inteligência são aqueles que por meio de sua formação se apropriaram de saberes institucionalizados. Essa superioridade da inteligência é apontada por Rancière (2007) como fictícia, uma vez que foi convencionada pelo contexto social para estabelecer padrões, valores e normas para uma sociedade. A partir dessas reflexões, nesta subseção, discorro a respeito das relações e da negociação de saberes entre os participantes desta pesquisa baseada em Rancière (2007), Santos (2010), Maciel (2013; 2014a), Mignolo (2000), dentre outros.

Conforme mencionado anteriormente neste trabalho, baseado no reconhecimento da pluralidade de conhecimentos heterogêneos e as interações entre eles, Santos (2010) propõe o conceito de ecologia de saberes. Essa ecologia consiste, segundo o autor, em "um conjunto de epistemologias que partem da possibilidade da diversidade e da globalização contra-hegemônicas e pretendem contribuir para as credibilizar e fortalecer" (SANTOS, 2010, p. 154).

No contexto desta pesquisa, noto os conhecimentos não institucionaliza-

8 Essa visão da professora vai ao encontro dos objetivos do Pibid, uma vez que o Programa visa tanto a fomentar a iniciação à docência de estudantes dos cursos de licenciatura de Instituições de Educação Superior quanto a contribuir para a formação continuada dos professores da educação básica. 
dos validados em duas diferentes perspectivas. A primeira diz respeito à postura da professora em abrir mão dos privilégios concedidos pela posição que ocupa e validar os conhecimentos trazidos pelos licenciandos. Em contextos mais tradicionais, possivelmente, esses saberes não seriam valorizados, e os licenciandos poderiam ser considerados não aptos a fazerem sugestões e interferirem nas escolhas da professora, em razão de ainda estarem em processo de formação profissional. Presumo que essa postura da professora contribuiu para que os licenciandos pudessem perceber-se como sujeitos de seu processo de formação docente. Remeto à defesa de Freire (1997) de que os indivíduos desempenhem papel ativo na construção de conhecimento e percebam-se não apenas como objetos, mas também sujeitos em suas relações de aprendizagem.

O segundo aspecto, diz respeito à posição tradicionalmente reconhecida como privilegiada que ocupo como pesquisadora por estar vinculada à universidade, instituição que representa o 'saber válido'. Embora estivesse nessa posição, conforme mencionado anteriormente, não tive como objetivo silenciar as vozes dos demais participantes ou apresentar respostas prontas e soluções para os impasses da escola e das salas de aula. O que se pretendeu foi a escuta sensível na busca por compreender o contexto do outro e perceber como interfere nas leituras e sentidos construídos (MACIEL, 2014a).

Nesse sentido, apresento alguns excertos em que identifico características das relações e negociação de saberes ao longo da investigação. Nos trechos abaixo, a professora Larissa ressalta a importância das contribuições dos licenciandos para o planejamento das aulas:

PS: Como já está pronto para esse mês, os próximos vocês podem me ajudar... Ah professora eu conheço essa música que tem esse conteúdo, ou tem um videozinho interessante, tá? Até porque mais pra frente eu quero trabalhar a questão de discriminação, então tem algo assim bem interessante, ou algumas perguntas relacionadas a isso. Assim... uma ajuda para elaborar uma aula. O que que vocês acham?

PS: Até porque às vezes eu monto uma aula, que que seria interessante, às vezes você enxerga de uma maneira diferente, você tem uma outra ideia, você tem um outro vídeo e eu nunca vou saber assim, por isso eu acho legal assim, a minha aula passa pra você se você tiver alguma coisa a mais para acrescentar, uma sugestão, passa pra ela...

PS: A gente tem que preparar para o próximo bimestre [...] Porque aí seria interessante vocês participarem do planejamento porque vocês têm um monte de ideias.

PS: E assim, sugestões também, eu acho importante. Até porque às vezes vocês têm uma visão que eu não estou tendo, né? Fiquem à vontade. 
Esses excertos ilustram os vários momentos em que a professora incentivou a participação ativa dos licenciandos durante as reuniões do grupo, seja por meio de sugestões e ideias para as aulas ou de opiniões sobre suas propostas. Essa postura reflete o reconhecimento e a valorização da infinita pluralidade dos saberes que, segundo Santos (2010), contribui para a realização de ações verdadeiramente emancipatórias.

A valorização dos saberes dos licenciandos levou à criação de um ambiente de formação propício à emergência de diferentes vozes. Saliento que, nos primeiros encontros do grupo, os licenciandos falavam pouco, talvez por pensarem que estavam ali apenas para aprender ouvindo e observando a supervisora. Entretanto, ao perceberem que seus conhecimentos e experiências eram valorizados, mostraram-se mais seguros e participativos. Sobre esse aspecto, apresento alguns excertos em que os licenciandos discorrem a respeito da receptividade a seus saberes por parte da professora:

$D:$ Ah, ela sempre foi aberta a isso, um ponto ótimo, porque a gente trazia e ela estava aberta a receber as nossas escolhas. Ela sempre esteve aberta a receber o que a gente tava falando ou as sugestões, isso!

A: É uma atitude democrática, acredito que ela tem essa postura no sentido de querer agregar mais [...] a partir da nossa fala ela quer agregar valor à aula dela, a partir também do que a gente pode contribuir.

\begin{abstract}
A: (Risos) Eu particularmente enquanto acadêmico, e tem também a questão do inglês que eu comecei a aprender ano passado, de fato, de certo modo me senti um pouco inibido sim no começo, mas é lógico que é uma nova experiência, é algo novo que veio agregar realmente! Veio agregar valor, veio agregar conhecimento, veio agregar assim, prática. Mas no começo eu me senti inibido sim, em todo o tempo laula e planejamento), é tudo novo, né? Eu nunca tive isso! Nada assim que com a vivência a gente não vá derrubando, nada que, não é um monstro de sete cabeças, a gente vai, e a vivência, de tá junto e tá elaborando uma aula em conjunto (grifos meus).
\end{abstract}

Conforme apontado pelos licenciandos nos excertos acima, todos participávamos das discussões e as decisões eram tomadas de forma coletiva. Em relação à minha participação no grupo, apresento a seguir trechos em que licenciandos e professora tecem alguns comentários:

R: Foi ótima, ajudou bastante a gente. Porque assim, às vezes passa um tema aí a gente fica sem ideia, aí você ajuda bastante nessa questão.

$P S$ : Eu acho também muito positiva, até porque você tem muitas ideias, né? Você já deu aula também, então você não é aquela pessoa que simplesmente tá estudando, mas nunca esteve na sala de aula. 


\begin{abstract}
Por que acontece isso! Então você traz muita coisa, muito material, até pra eles também, né? Uma pessoa, uma profissional, que eles podem também até se se espel harem, ver o jeito que você trabalhou. Então assim, você simplesmente terminei a faculdade, tô fazendo um mestrado, de repente não teria muita coisa para acrescentar, mais teoria. Mas você é uma pessoa que nos ajuda muito! E a gente fica muito a vontade com a sua presença também!

$D$ : Ah eu acho que foi positiva também, porque você tava sempre com suas ideias, sempre trazendo uma coisa nova. No começo a gente fica inseguro mesmo, porque tem uma pessoa que tá avaliando a professora e a gente (risos).

$P$ : Avaliando?

D: é tipo tá avaliando, tá cuidando, pela sua postura e tudo, a gente fica preocupada. (risos) eu fico. Mas assim, foi sempre ótimo, sempre contribuiu, sempre mandou tudo ali pra eu ler, pra eu fazer o meu trabalho, foi muito positivo (grifos meus).
\end{abstract}

De modo geral, eu (pesquisadora) me sentia bastante à vontade e sempre participava das discussões nas reuniões de planejamentos. Entretanto, conforme observo nos relatos acima, embora em alguns momentos (presencialmente ou via grupo fechado do Facebook) tivesse compartilhado algumas considerações teóricas, minha maior contribuição, segundo eles, consistiu no que denominaram "ideias" para aulas. Essas ideias foram sugestões de temas, atividades e materiais, um reflexo, certamente, de minhas leituras e experiências em sala de aula.

A professora Larissa aponta como um aspecto positivo o fato de eu não ser uma pesquisadora sem experiência em sala de aula e demonstra acreditar na possibilidade de essa vivência me permitir um olhar mais sensível ao seu contexto. Identifico ainda na fala da professora uma crítica ao pesquisador que, conforme aponta Maciel (2013), adentra a escola com a intenção de levar respostas prontas e soluções, mesmo desconhecendo o contexto. Nesse mesmo excerto, interpreto a partir do seguinte comentário "então assim, você simplesmente terminei a faculdade, tô fazendo um mestrado, de repente não teria muita coisa para acrescentar, mais teoria", as expectativas da professora em relação à universidade. Posso inferir que se trata de uma tentativa da professora de expressar que a escola tem expectativas em relação à universidade por algo que vá além de teorias, como ações voltadas para o contexto.

Outra questão que me chama a atenção diz respeito à insegurança inicial exposta pela licencianda Débora. Conforme relatado por ela, esse sentimento estava associado à percepção que ela teve de que eu [pesquisadora] participava das reuniões do grupo e das aulas com o objetivo de avaliar a professora e os licenciandos. Associo esse sentimento à discussão de Rancière (2007) e Santos 
(2010) quanto à hierarquização que resulta da valorização dos conhecimentos institucionalizados e que leva à desigualdade e à exclusão. Um sentimento que surgiu, embora em momento algum alguém tenha mencionado que eu estava ali para avaliá-los.

De modo geral, em programas de formação de professores com características 'tradicionais' é comum que se preservem relações hierárquicas de conhecimento, de experiência ou de liderança (MACIEL, 2014a). Isso ocorre, de acordo com Santos (2010, p. 137), em razão de "as formas privilegiadas do conhecimento conferem [irem] privilégios extra-cognitivos (sociais, políticos, culturais) a quem as detém". Nessa perspectiva, a posição hierárquica dos participantes determina seus papéis ao longo dos processos de formação.

Remeto ainda a relação entre os diferentes saberes, no contexto investigado, à crítica de Mignolo (2000) à colonialidade do poder e aos processos de subalternização de saberes, povos e culturas. $\bigcirc$ autor defende o resgate de saberes silenciados por meio da gnose liminar, uma reflexão crítica, que segundo ele, é "razão subalterna se esforçando para trazer para o primeiro plano a força e criatividade dos saberes subalternizados" (MIGNOLO, 2000, p. 13). A compreensão da relação entre esses saberes, de acordo com Mignolo (2000, p. 110), é fundamental para o pensamento marginal, "um outro modo de pensar", realizado a partir das "margens". Esse pensamento, segundo o autor, pode possibilitar a emergência de vozes, línguas e culturas sem que outras precisem ser silenciadas ou excluídas.

Esse pensamento age a partir e entre as várias histórias locais e que redefine a geopolítica do conhecimento. Remetendo ao contexto investigado, considero importante destacar que o olhar para o contexto escolar é que aponta o rumo das escolhas do grupo. Percebo que, segundo discutido por Mignolo (2000), os ditos saberes hegemônicos são confrontados pelos saberes subalternos, em outras palavras, em vez de os saberes científicos serem a principal diretriz para planejamento das aulas, são as necessidades do contexto.

Em entrevista, os participantes comentaram suas impressões em relação às características da formação docente da qual participaram e à postura da professora na condução do grupo:

L: Bom, a elaboração nós fizemos em conjunto, a gente participou do planejamento dela. Então assim, eu me sentia até valorizada quando eu participava do planejamento, porque em outras oportunidades eu não tive essa possibilidade, né? Então assim, eu gostei, eu não sabia como funciona. Porque um dos meus medos era não saber isso, então ela me mostrou várias coisas pequenas, mas que são importantes no planejamento, na condução da sala de aula, que eu não sabia, que eu não imaginava que era daquela forma. Mas, é... foi muito bom assim. 
A: A gente senta, a gente planeja tudo junto, é tudo de comum acordo e as escolhas que ela tem feito, lógico ela leva em conta as experiências dela, né? Aquilo que ela tem vivido na escola, que ela tem praticado ao longo dos anos, e a gente concorda em relação a isso, porque a gente entende que está na prática aqui, a gente tá se formando, mas não que a nossa opinião também não seja válida. Em todo tempo ela tem levado também em conta a nossa opinião e o que a gente pode trazer de bom para a aula (grifos meus).

Como posso depreender dos excertos acima, a possibilidade de participar do planejamento, não apenas como observadores, mas emitir opiniões e sugerir temas e atividades, foi avaliada como positiva pelos licenciandos. Um dos participantes acrescentou que teve a percepção de que a professora supervisora tinha a intenção de realmente prepará-los para a sala de aula.

L: Ela que deu a direção, então a postura dela foi assim de uma líder, mas que de certa forma nos permitia algumas coisas que outras professoras e outros programas não permitem. Então, assim, ela foi nos orientando, né? Acho que a intenção dela foi nos preparar realmente para a sala de aula, então, fundamental.

D: A gente teve as escolhas, daí nós trouxemos alguns materiais, ela dava algumas dicas de material, a gente trazia também, a gente ajudou no planejamento. O planejamento também nunca tinha feito nada, em nenhuma matéria na faculdade, mas na prática é bem diferente, é bem melhor você ver como é que faz o planejamento, dia tal tema tal e vamos aplicar isso, dava certo. A experiência que a gente teve foi que a gente pode participar, trazer nossas ideias, trazer material, ela também dava algumas ideias pra gente de como a gente fazer esse planejamento, de como que pode ser feito. [...]Acho que eu dou conta de fazer um planejamento sozinha, planejamento eu acho que sim. É igual eu falei as ideias às vezes parece que elas não tão encaixando, mas acho q tá melhorando.

A: A gente senta, a gente planeja tudo junto, é tudo de comum acordo
e as escolhas que ela tem feito, lógico ela leva em conta as experiências
dela, né? Aquilo que ela tem vivido na escola, que ela tem praticado ao
longo dos anos, e a gente concorda em relação a isso, porque a gente
entende que está na prática aqui, a gente tá se formando, mas não que
a nossa opinião também não seja válida. Em todo tempo ela tem levado
também em conta a nossa opinião e o que a gente pode trazer de bom
para a aula. (Grifos meus)

A partir dos excertos apresentados, interpreto que foi o enfraquecimento da hierarquia pesquisadora e pesquisada e professora supervisora e licenciandos que permitiu o desenvolvimento de um trabalho colaborativo. Segundo Takaki (2012, p. 88), esse enfraquecimento de hierarquia ocorre na fissura dos diálogos e abre espaço "para práticas colaborativas, éticas e políticas que melhorem as vi- 
das de ambos e da coletividade". Atribuo a emergência e o compartilhamento de saberes que contribuíram para a produção das aulas à atenuação de hierarquia observada na relação pesquisadora, professora e licenciandos. Nesse mesmo raciocínio, Freire (1987, p. 78) defende

Como também não lhe seria possível fazê-lo fora do diálogo. É através deste que se opera a superação de que resulta um termo novo: não mais educador do educando, não mais educando do educador, mas educador-educando com educando-educador. Desta maneira, o educador já não é o que apenas educa, mas o que, enquanto educa, é educado, em diálogo com o educando que, ao ser educado, também educa.

Associo esse diálogo sugerido por Freire (1987) à defesa de Rancière (2007) pelo reconhecimento e valorização dos diferentes saberes. No contexto investigado, os conhecimentos institucionalizados são valorizados, entretanto, não silenciam os saberes originários da escola. A professora é receptiva aos saberes dos licenciandos e da pesquisadora, entretanto, são os conhecimentos locais que determinam o que será ensinado durante as aulas. A pesquisadora não adentra a escola com o objetivo de ensinar os demais participantes, nem os licenciandos apenas aprendem, a professora, a relação permite trocas pelas quais todos ensinam e aprendem durante todo o processo. Um modelo que contraria uma lógica tradicional de formação de professores. Os conhecimentos da professora da escola contribuem para a formação dos licenciandos e da pesquisadora sobre ensinar inglês na escola pública.

Ao abordarmos a formação de professores, segundo Maciel (2014a), o conceito de emancipação ganha centralidade. Com base nos argumentos de Rancière (2010) e Biesta (2010), o autor discute um trabalho de formação de professores que considere o aspecto local em que a emancipação não está relacionada em um pensamento vertical ao se considerar o outro. Nesse sentido, o autor aponta que

O processo de emancipação, por sua vez, estaria na ação crítica de explorar alternativas e não no propósito de se buscar uma verdade e uma autenticidade. Por essa ótica, os conceitos [verdade e autenticidade] são considerados questionáveis e, por conseguinte, entende a verdade como contingente, complexa, dinâmica e situada. Essa nova lógica poderia também estar relacionada ao aspecto de desconstrução que visa questionar o que temos como certo, para então perceber o que se faz singular, contingente e produto de restrições arbitrárias. Valoriza-se, nesse caso, a pluralidade e a multiplicidade de explicações para os fatos, para os eventos, para as interrelações e para os domínios de diferença (MACIEL, 2014b, p. 263). 
Nessa perspectiva, segundo Maciel (2013, p. 144), "a ação crítica estaria relacionada em se perceber algo que representa apenas uma faceta das várias possibilidades". De acordo com esse raciocínio, "não é papel do emancipador [pesquisador] libertar o outro [professor], mas expô-lo a uma oportunidade igual, experimental para todos [inclusive para o próprio pesquisador]" (MACIEL, 2013, p. 144). Essa perspectiva, segundo o autor, corresponde à noção de emancipação revisitada, que tem por objetivo "empoderar os alunos [professores] a ter controle de suas próprias agendas educacionais", conforme apontado por Biesta (2010, p. 78).

Baseado em Rancière (2010), Maciel (2014b, p. 263) aponta ainda que "a premissa da emancipação visa a tornar os indivíduos independentes e autônomos, que pensem por si mesmos, que fazem seus próprios julgamentos e que cheguem a suas próprias conclusões". Nesse caso, "a emancipação não é feita para, mas por pessoas, ou seja, nós nos emancipamos", em um processo em que segundo o autor, pesquisador e professor "assumem papéis em direção a uma lógica de igualdade, construção de agência e autoempoderamento" (MACIEL, 2014b, p. 266).

No encerramento das atividades da etapa investigada do Subprojeto Letras-Inglês, pedi aos licenciandos para comentarem a experiência de participar do Pibid. Seguem trechos das entrevistas:

D: Eu acho que o projeto foi muito bom para ter essa experiência, que eu nunca tive nada, então foi assim o que abriu as portas, pra escola, pra ver como que é, eu acho que foi um ponto positivo participar do projeto. Foi uma boa escolha que eu fiz esse ano, foi ter me inscrito e participado, uma escolha bem feita. Abriu mais uma porta pro que eu quero, um passo a mais para o que eu vou fazer no futuro, foi ótimo!

L: Eu acredito que ultrapassou as minhas expectativas, porque eu aprendi coisas novas, né? Eu vi que não é só um jeito que existe, que a gente pode inovar, que a gente pode trazer outros temas, assuntos, coisas novas para a sala de aula. Que a gente pode colocar isso, é...fazer um paralelo com a vida do estudante, né? Se preocupar com a parte social também.

$R$ : É bem interessante e já contribui para as nossas escolhas futuras, né? De como nós vamos fazer mais pra frente, eu me sinto feliz dessa parte de poder dar opinião, de poder participar tudinho. [...] é bem ousado da professora fazer isso, assim é, a gente tá ainda em formação, não tem uma vivência com a sala de aula, agora que a gente tá tendo esse contato e ainda não dando aula, [...] assim é uma coragem que a professora coloca, é uma responsabilidade que a gente tem de também buscar os temas tudinho.

A: Hoje eu penso que um professor, ele deve provocar mais, deve perguntar mais, ele não deve dar uma palestra, no gênero de dar uma palestra de aula, né? É onde eu tinha essa ideia e agora isso tem mudado um pouco, com certa resistência minha porque eu não consigo vislumbrar essa aula muito provocadora, provocativa no aluno, né? Mas 
acho que agora dá para começar a mudar essa concepção e tentar praticar num segundo momento. [...] Eu ainda não sei como fazer isso! (grifos meus).

Observo nos trechos acima que, para Débora, participar do Pibid foi uma boa experiência, pois possibilitou adentrar o contexto escolar, o que, segundo ela, representou mais um passo para a profissão que pretende exercer. Lidiany mencionou que aprendeu coisas novas durante o processo de formação, dentre as quais destacou a possibilidade de inovar, levando para a sala de aula temas e assuntos que permitam aos estudantes diferentes formas de aprendizagem e transformação social. Rhullielton enfatizou que participar de um planejamento colaborativo de aulas foi uma experiência interessante e que contribuirá para escolhas futuras em sua prática docente. Já André refletiu sobre o perfil do professor para o cenário atual, um profissional que não apenas transmite informações aos alunos, mas que thes permite participar ativamente de seus processos de aprendizagem.

\section{Considerações Finais}

Conforme comentários dos licenciandos que encerram a seção anterior, foram objeto de análise e discussão da pesquisa, o foco das aulas, a reconfiguração das relações em sala de aula e a formação e agência docente. Nesse sentido, considero que os resultados deste trabalho podem suscitar reflexões sobre a formação de professores nos seguintes aspectos: A valorização da ecologia de saberes, que tem como premissa o reconhecimento de uma pluralidade de formas de conhecimento (SANTOS, 2010), em contexto de formação de professores, pode resultar em ações colaborativas de construção de sentidos. E, no processo colaborativo, não é papel do pesquisador libertar o professor ou dar respostas prontas para o contexto que lhe é desconhecido, mas por meio de uma escuta sensivel tentar entender o contexto do outro. E por meio de uma oportunidade igual e experimental para ambos, perceber como o conhecimento local pode interferir nas percepções do pesquisador e vice-versa (MACIEL, 2014a).

Em suma, as transformações no mundo contemporâneo nos diferentes âmbitos da sociedade geraram novas demandas no que se refere à formação de alunos e professores. Menezes de Souza (2011) afirma que as complexidades com que nos deparamos nesse cenário apontam para constantes reflexões sobre a prática docente e para a busca de novas formas de atuação. Essas foram ques- 
tões que me motivaram a realizar este trabalho que contribuiu para a formação dos licenciandos e para a ampliação de perspectivas teórico-práticas da professora supervisora e desta pesquisadora. Saliento que os estudantes das turmas participantes também foram beneficiados com aulas que permitiram a expansão de visões acerca dos temas debatidos, além da aprendizagem contextualizada do idioma.

Por fim, informo ao leitor que as proposições aqui apresentadas consistem na minha percepção, por meio de um olhar situado sócio-historicamente (MACIEL, 2014a; MENEZES DE SOUZA, 2011) e, por essa razão, são verdades situadas, contingentes e fracas (VATTIMO, 1985; 2004 apud MACIEL, 2013), portanto, passíveis de outras leituras e interpretações.

\section{Referências}

BIESTA, G. J. J. Good Education in the age of measurement: Ethics, politics and democracy. London: Paradigm Publishers, 2010.

BRASIL. Orientações Curriculares para o Ensino Médio: Línguas Estrangeiras. In: Linguagens, Códigos e Tecnologias. Brasília: MEC, 2006. Disponível em: http://goo.gl/RxeyS3. Acesso em: 20 jul. 2014.

CRAWSHAW, R. Intercultural awareness as a component of HE Modern Language courses in the UK, 2005.

DUBOC, A. P. M. Atitude Curricular: Letramentos Críticos nas brechas da formação de professores de inglês. 2012. 246 f. Tese (Doutorado) - Programa de Pós-Graduação em Estudos Linguísticos e Literários em Inglês do Departamento de Línguas Modernas da Faculdade de Filosofia, Letras e Ciências Humanas da Universidade de São Paulo- USP, 2012.

DUBOC, A. P. M. O ensino de línguas estrangeiras na contemporaneidade: teorias em prática. Palestra proferida no VI EPLIMS. Campo Grande, MS, 04 de novembro de 2011.

FREIRE, P. Pedagogia do oprimido. 17. ed. Rio de Janeiro, Paz e Terra, 1987.

FREIRE, P. Pedagogia da autonomia: saberes necessários à prática educativa. São Paulo: Paz e Terra, 1997.

JORDÃO, C.; FOGAÇA, F. C. Ensino de inglês, letramento crítico e cidadania: um triângulo amoroso bem-sucedido. Línguas e Letras, Cascavel-PR, v. 8, n. 14, p. 79-105, 2007.

KALANTZIS, M. COPE, B. New learning: Elements of a science of education. Second edition. Port Melbourne, Victoria, 2012.

MACIEL, R. F. Letramento crítico das políticas linguísticas e a formação de professores de línguas. In: Nara Hiroko Takaki; Ruberval Franco Maciel. (Org.). Letramentos em Terra de Paulo Freire. Campinas: Pontes, 2014a. 
MACIEL, R. F. "Eu sei o que é bom pra você!" A lógica da emancipação revisitada e a formação de professores. In: ZACCHI, V. J.; STELLA, P. R. (Orgs.). Novos letramentos, formação de professores e ensino de língua inglesa. Maceió: Udufal, 2014b, v. 1, p. 247-268.

MACIEL, R. F. Negociando e reconstruindo conhecimentos e práticas locais: os documentos oficiais e a formação de professores de inglês. 2013. Tese (Doutorado) - Programa em Estudos Linguísticos e Literário de Inglês, USP, 2013.

MATTOS, A. M. A.; VALÉRIO, K. M. Letramento crítico e ensino comunicativo: lacunas e interseções. Revista Brasileira de Linguística Aplicada, v. 10, n. 1, p. 135-158, 2010.

MENEZES DE SOUZA, L. M. T. O professor de inglês e os letramentos no século XXI: métodos ou ética? In: JORDÃO, C.M., MARTINEZ, J. Z., HALU, R. C. (Orgs.). Formação “desformatada": práticas com professores de língua inglesa. Campinas: Pontes Editores, 2011, p. 279-303.

MIGNOLO, W. D. Local histories/global designs: coloniality, subaltern knowledges and border thinking. Princeton, NJ: Princeton University Press, 2000.

MILLER, I. K. Formação de professores de línguas: da eficiência à reflexão crítica e ética. In: LOPES, L. P. da M. (org.). Linguística Aplicada na modernidade recente: festschrift para Antonieta Celani. São Paulo: Parábola, 2013, p. 99-121.

MONTE MÓR, W. M. Caderno de Orientações Didáticas para EJA: Línguas Estrangeiras. 1. ed. São Paulo: SME, 2010. v. 1, 146 p. Disponível em: http://goo.gl/TfSXFd. Acesso em: 18 ago. 2014.

MONTE MÓR, W. M. Eu e o outro: imagens refletidas. Um estudo sobre identidade e alteridade na percepção das culturas, Interfaces, Rio Grande, n. 8, 2008, p. 161-180.

MONTE MÓR, W. M. Investigating critical literacy at the university in Brazil. Critical Literacy: Theories and Practices, v. 1, n. 1, p. 41-51, 2007. Disponível em: http://goo.gl/gmyy9e. Acesso em: 20 dez. 2014.

RANCIÈRE, J. O mestre ignorante: Cinco lições sobre a emancipação intelectual. Belo Horizonte: Autêntica, 2007.

SANTOS, B. S. A gramática do tempo: para uma nova cultura política. 3. ed. São Paulo: Cortez, 2010.

SILVA, S. B. Da técnica à crítica: contribuições dos letramentos críticos para a formação de professores de língua inglesa. Porto Alegre: Editora da Oficina, 2012.

TAKAKI, N. H. Da metodologia de pesquisa em letramentos e sociedade para a ética: implicações na formação continuada da comunidade científica. Polifonia, Cuiabá, MT, v. 19, n. 25, p. 87-110, jan./jul., 2012.

TODD, S. Learning from the Other: Levinas, psychoanalysis, and ethical possibilities in education. New York: Suny Press, 2003. 


\section{Sobre o autor}

Themis Rondão Barbosa da Costa Silva - Doutoranda em Linguística Aplicada pela Universidade Estadual de Campinas (Unicamp). Professora do Ensino Básico, Técnico e Tecnológico (EBTT) do Instituto Federal de Mato Grosso do Sul (IFMS); Mato Grosso do Sul MS. E-mail: themis.barbosa@ifms.edu.br. Lattes: http://lattes.cnpq.br/0093071321086264 OrclD: https://orcid.org/0000-0002-2296-9387. 